\title{
Intensification of the Banana Drying Processes by Using EFL Electromagnetic Waves
}

\author{
Arif Memmedov, Teymuraz Abbasov, Mustafa Şeker \\ Department of Electric-Electronic Engineering, Faculty of Engineering, University of Inonu, Malatya, Turkey \\ Email: arif.memmedov@inonu.edu.tr, teymuraz.abbasov@inonu.edu.tr, mustafaseker0@gmail.com
}

Received 27 March 2016; accepted 20 May 2016; published 23 May 2016

Copyright $(\underset{2016}{ } 20 y$ authors and Scientific Research Publishing Inc.

This work is licensed under the Creative Commons Attribution International License (CC BY). http://creativecommons.org/licenses/by/4.0/

(c) (i) Open Access

\begin{abstract}
Drying of the banana in the hot water has a negative impact on the quality of the product and drying effect. The purposes of this study are increasing the drying rate, using the relatively low temperature to improve the quality $\left(40^{\circ} \mathrm{C}, 50^{\circ} \mathrm{C}\right.$ and $\left.60^{\circ} \mathrm{C}\right)$ and investigate the use of electromagnetic waves to increase the drying speed. Therefore, experiments are performed using $5 \mathrm{kHz}, 10 \mathrm{kHz}$ and $15 \mathrm{kHz}$ low frequency electromagnetic waves in the air velocity values of $0.5 \mathrm{~m} / \mathrm{s}, 1 \mathrm{~m} / \mathrm{s}, 1.5$ $\mathrm{m} / \mathrm{s}$ and $2 \mathrm{~m} / \mathrm{s}$ and $40^{\circ} \mathrm{C}, 50^{\circ} \mathrm{C}, 60^{\circ} \mathrm{C}$ centigrade degrees of air blast in a special compartment. Mathematical model of the drying process has been created as using the electrical circuits methods and experimental results. As a result, a simple equation describing the drying process has been obtained. Nonlinear expression of the diffusion coefficient for a different situation in this equation has been identified for the first time. The obtained theoretical results and experimental results have been provided a good agreement. This study is considered to be useful for all studies in the drying area.
\end{abstract}

\section{Keywords}

Electromagnetic Wave, Drying Process, Heat and Mass Transfer, Frequency, Banana Drying

\section{Introduction}

Microorganisms absolutely require the water for their metabolism as it is all living being. All fruit and vegetables are containing a good environment for the life of microorganism because they involve $70 \%-80 \%$ water in their structure. These microorganisms lead to very short life time for fruit and vegetables and these fruit and 
vegetables are deteriorate in a short time and don't use. One of the long-term protection methods of fruit and vegetables is cast out the water in their composition by way of drying. In this way, environment is brought to unfavorable situation in terms of water for microorganisms.

Approximately 20 percent of dried fruits and vegetables are having moistness. In practice, fruit and vegetables are dried using natural (like sun drying) or industrial methods (dehydrated etc...).

Dried fruits are very rich in A, B1, B2, B3, B6 vitamins and iron, calcium, magnesium, phosphorous and stored for a long period of time without being a cold environment. This feature is most important advantages of drying fruit and vegetables and these fruits and vegetables always available as an alternative differ from fresh fruits and vegetables. On the other hand, the drying process should be taken into account that the loss of a large portion of the vitamin C.

Dried fruit and vegetables in the food industry are used for purposes such as breakfast, meals and snack. These vegetables and fruits are generally having a special aroma and sweet or sour taste because of lost large part of the natural moistness in the drying time [1] [2].

Dried vegetables and fruits in the industry are subjected to steam with sulfur dioxide vapor to prevent to storing the color and distortion. In order to obtain results of high quality in terms of technology should be used quality fruit and vegetables as material. In other words, the drying process of immature or too mature vegetables and fruits is impossible to high-quality results. It is therefore drying time and temperatures are very important in the drying process. Increasing the drying time causes a change of color of the resulting dried fruit and temperature increase indicates a significant impact on the quality of dried vegetables and fruits.

One of the fruit is used widely and highly perishable is bananas. Bananas are usually produced in developing country. The loses of fruit and vegetables production in this countries are estimated to be about $30 \%-40 \%$ (jayaramanandcupta 1955) and this rate is very high. For this reason, developing the new methods for reducing that loses is very importance. One of the long term preservation method of fruits and vegetables is physic-chemical drying method.

Drying process of fruit and vegetables have been studied by many researchers and obtained results have been published in the scientific literature in the form of hundreds articles and books. In this study, it has been created different mathematical and experimental models using both general theories of the drying process and classical equation of mass and heat transfer. In the some studies. They are taken into the consideration temperature changes and effects adjustment of the blowing air velocity for accelerating the drying process.

In this study, it is taken considering the effects of low-frequency electromagnetic waves and to accelerate the drying process and laboratory model of the dryer has been prepared. This model has been used in experiments. The effectiveness of the model applied has been examined by comparing the theoretical and experimental results.

\section{Mathematical Model of Drying Process}

Material in the process of the drying bananas to be placed drying networks as separated into segments of 9 - 10 $\mathrm{mm}$. The fallowing assumptions have been used in order to simplify the establishment of the model:

1) Mass and heat transfer is one-dimensional.

2) Distribution of the air in the drying process is homogeneously and speed of air is constant.

3) Any chemical reaction does not occur in the drying process.

4) The amplitudes of the electric and magnetic components of the electromagnetic field is constant in the drying process.

Banana layer in $10 \times \emptyset ́ 25 \mathrm{~mm}$ measurement placed in $T_{\infty}\left(T_{m}\right)=$ constant laminar air flow is shown in the Figure 1. Air temperature will be transmitted in the $y$ direction because of air blowing is along the $y$ axis. Instantly $t=0$ due to the effect of electromagnetic fields on the layer will consist an electromagnetic wave along the $z$ axis. Electromagnetic wave (EMW) that occurred is assumed to be homogeneous on account of the effect of electromagnetic fields for banana layer is less depending on the amount of liquid. When the decrease the amount of liquid in the layer of composition, EMD's effect will be reduce.

$T_{0}$ and $T_{2 \delta}$ temperature in the upper and lower layers of the banana layer in Figure 2 are equal to blowing air temperature and is taken to be $T_{m}$. The temperature in the slice $T(d)$ varies nonlinearly as depending on the internal structure and thickness of the material. Therefore, the measurement of it is difficult and cannot be taken instantly. For this reason $T(d)$ temperatures is taken as constantly and commensurate with $T_{m}$. When material dries, it's shape is changes, it shrinks and becomes a different geometry. 


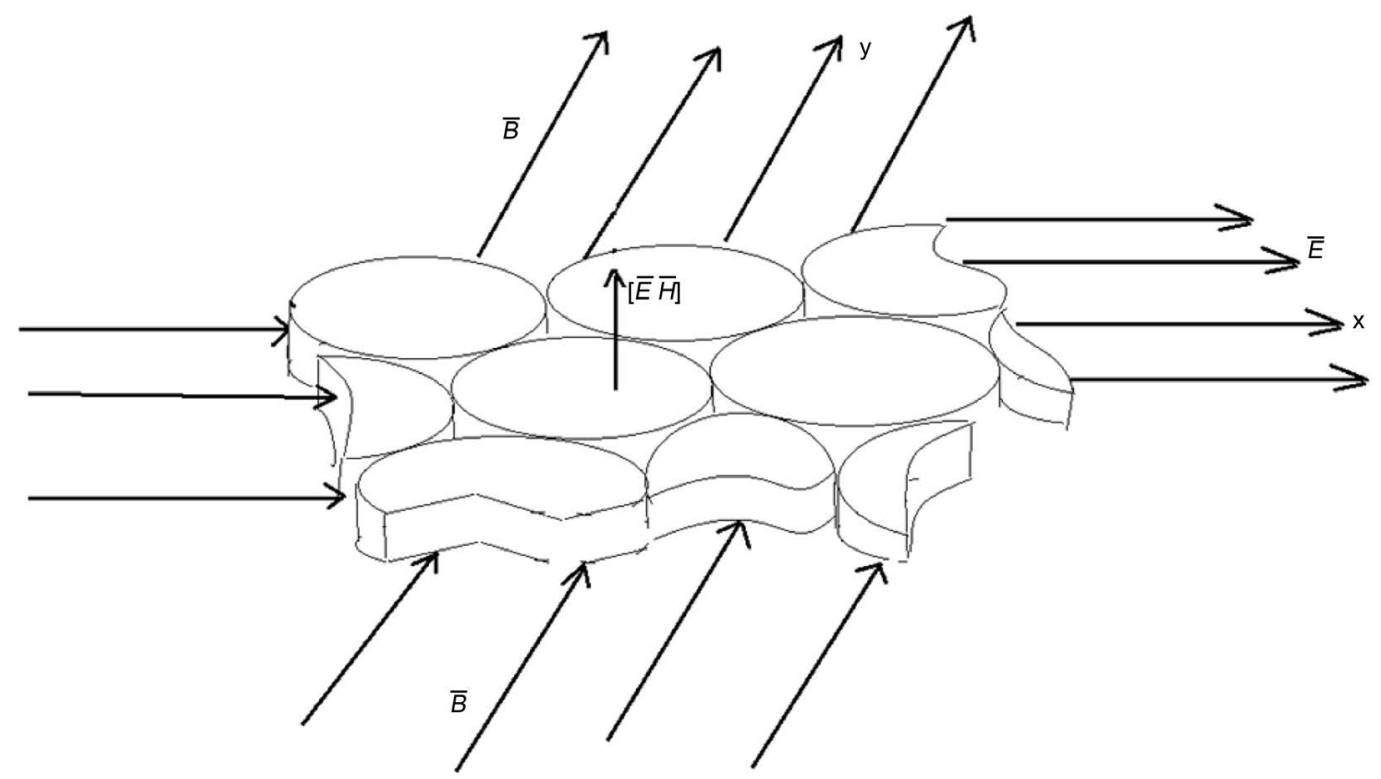

Figure 1. The Placement of banana slice in a layer for control portion and aspects of the electromagnetic field vectors affecting the banana slices.

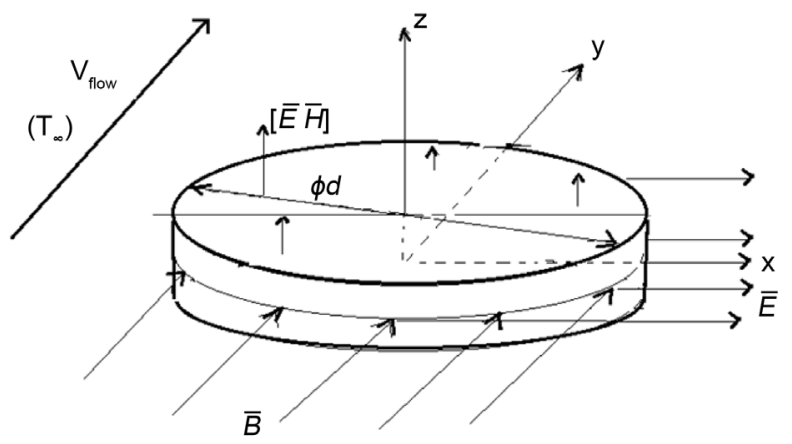

(a)

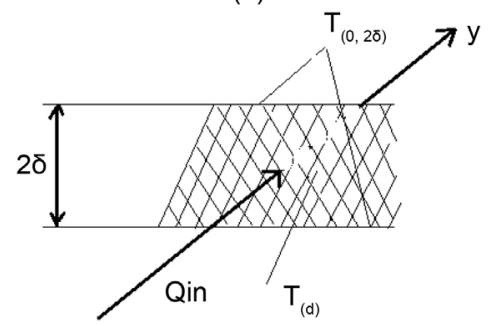

(b)

Figure 2. The forces acting on the banana slices in dryer (E electromagnetic field).

All edges of the slice is deformed in the drying process and is seen that deformation along of the $z$ axis. Thus the mass equation of drying material can be written as fallow:

$$
\begin{aligned}
& \frac{\partial M}{\partial t}+V \frac{\partial M}{\partial z}=D_{e f f} \frac{\partial^{2} M}{\partial z^{2}}+D_{e l m} \frac{\partial^{2} M}{\partial z^{2}} \\
& \frac{\partial T}{\partial t}+U \frac{\partial F}{\partial x}=\alpha \frac{\partial^{2} T}{\partial x^{2}}
\end{aligned}
$$

Temperature and physical process and diffusion coefficient of EMW are nonlinear and so it is not possible to solve the general form of Equation (1). 


$$
M=M^{\prime}+M^{\prime \prime}
$$

In this case, nonlinear differential equation of the expression (1) turns into the following form:

$$
\begin{aligned}
& \frac{\partial M^{\prime}}{\partial t}+V \frac{\partial M^{\prime}}{\partial t}=D_{\text {eff }} \frac{\partial^{2} M^{\prime}}{\partial z^{2}} \\
& \frac{\partial M^{\prime \prime}}{\partial t}+V \frac{\partial M^{\prime \prime}}{\partial t}=D_{e l m} \frac{\partial^{2} M^{\prime \prime}}{\partial z^{2}}
\end{aligned}
$$

wherein $M^{\prime}$ characterizes the amount of mass transfer taken as a result of convective diffusion and $M^{\prime \prime}$ has been determined the amount of mass transfer received as a result of diffusion effects of EMW. $M$ is characterized by the total amount of mass transfer. The general solution of Equation (3) and Equation (4) is presented in reference 20. In this study has been a conducted necessary arrangement for banana in the solution of theoretical and experimental results as those mentioned on above. The diffusion coefficients contained in this solution are determined empirically as considering the results of the experiment drying of the banana.

In the literature [1] [3]-[19], there are different methods for solving of heat and mass transfer equations. Each of these methods involves different correction coefficients using approximate solution methods. These investigations carry away theoretical character. The methods used in the practice are essentially empirical formula. Therefore, the results obtained from these methods are inadequate to explain the nature of the drying process in many cases. The method which is called two-part theories widely used in the solution of equations to be characterized by a similar mass transfer equations representing the drying process in the engineering practice [20] [21]. Its application to two-port theory which have simple structure and advanced investigation methods can facilitate the solution of these problems of the drying process. According to this theory constitute the equation of relationship between these two parameters in processes characterized by two input and two output. The coefficients of these two equations take into consideration also the size of physical process characterizing in the environment. To apply the two-port circuit model of the drying process, the volume of the dried material is considered a two-port format (Figure 3):

$\rho_{0}$-Density of the liquid mass exiting the volume as a result of diffusion;

$Q$-Liquid heat flow involved in the volume, Joules;

$Q_{0}$-heat flow exiting the volume with liquid vapour, Joules.

According to the theory of two-port circuits we can write the following equations for circuit in Figure 3:

$$
\begin{aligned}
& \rho=A_{11} \cdot \rho_{0}+A_{12} \cdot Q_{0} \\
& Q=A_{21} \cdot \rho_{0}+A_{22} \cdot Q_{0}
\end{aligned}
$$

here $A_{11}, A_{12}, A_{21}$ and $A_{22}$ are the coefficients of the two-port and these coefficients are determined as depending on physical and chemical properties of the material in the volume, their geometrical measurement, parameters that characterize the microstructure and physical process. These coefficients are determined according to the initial conditions. Coefficients of two-port circuit according to the initial conditions:

$$
\begin{aligned}
& A_{11}=\left.\left(\frac{\rho}{\rho_{0}}\right)\right|_{Q_{0}=0} ; A_{12}=\left.\left(\frac{Q}{Q_{0}}\right)\right|_{\rho_{0}=0} \\
& A_{21}=\left.\left(\frac{Q}{\rho_{0}}\right)\right|_{Q_{0}=0} ; A_{22}=\left.\left(\frac{Q}{Q_{0}}\right)\right|_{\rho_{0}=0}
\end{aligned}
$$

$Q, Q_{0}$ magnitudes in Equation (6) is arranged by the values obtained from trials and statements. With the

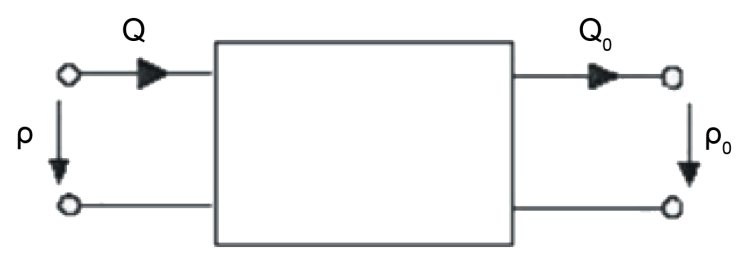

Figure 3. Basic diagram of a two-port circuit system. 
method which is demonstrated in reference [1] [12]-[14] [21]-[25] in material drying process.

\section{Results and Discussion}

Thus the fallowing equation is obtained for the mass transfer in the dried bananas.

1) The temperature of blown air average $T_{m}=313^{\circ} \mathrm{K}\left(40^{\circ} \mathrm{C}\right)$

According the external environment temperature to be $T_{\infty}=300{ }^{\circ} \mathrm{K}\left(27^{\circ} \mathrm{C}\right)$.

$\frac{T}{T_{m}} \cong 0.974$ becomes, mass change equation in this manner must have the following structure.

$$
\frac{M}{M_{0}}=\left\{1+\left[11.64 \cdot \frac{T}{T_{m}}\left(\frac{t}{t_{\infty}}\right)^{2}+120\left(\frac{f}{f_{\infty}}\right)^{2}\left(\frac{t}{t_{\infty}}\right)\right] \alpha(t)\right\}^{-1}
$$

wherein $\alpha(t)$ is nonlinear diffusion coefficient calculated empirically.

$$
\begin{aligned}
& f=0 \mathrm{kHz} \Rightarrow\left(\frac{t}{t_{\infty}}\right)^{2}=0 \Rightarrow \alpha(t)=(0.298) \times 1.45^{-\left(\frac{t}{t_{\infty}}\right)^{2}} \\
& f=10 \mathrm{kHz} \Rightarrow\left(\frac{t}{t_{\infty}}\right)^{2}=0.01 \Rightarrow \alpha(t)=(0.129916) \times 0.008^{-\left[\frac{t}{t_{\infty}}-\left(\frac{t}{t_{\infty}}\right)^{2}\right]} \\
& f=5 \mathrm{kHz} \Rightarrow\left(\frac{t}{t_{\infty}}\right)^{2}=0.025 \Rightarrow \alpha(t)=(0.13019648) \times 0.26^{-\left(\frac{t}{t_{\infty}}\right)^{2}} \\
& f=20 \mathrm{kHz} \Rightarrow\left(\frac{t}{t_{\infty}}\right)^{2}=0.04 \Rightarrow \alpha(t)=(0.1381256) \times 1.1^{-\left(\frac{t}{t_{\infty}}\right)^{2}}
\end{aligned}
$$

According to these results experimental and theoretical curves of drying the banana under the influence of EMW has been shown in Figure 4.

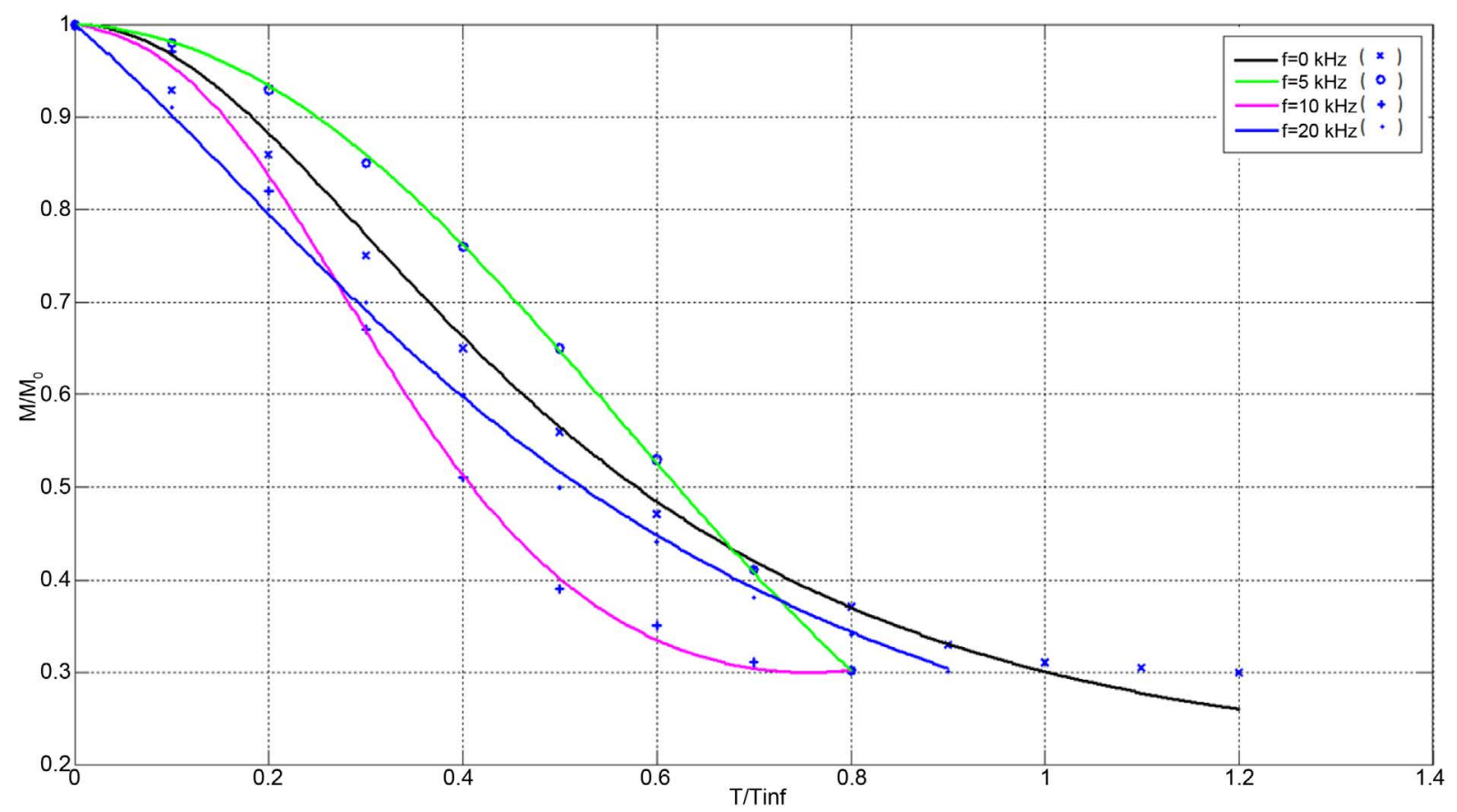

Figure 4. Experimental and theoretical curves of drying the banana under the influence of EMW for $T_{m}=313{ }^{\circ} \mathrm{K}$. 
2) The temperature of blown air average $T_{m}=323^{\circ} \mathrm{K}\left(50^{\circ} \mathrm{C}\right)$

According the external environment temperature to be $T_{\infty}=300{ }^{\circ} \mathrm{K}\left(27^{\circ} \mathrm{C}\right)$.

In case of $\frac{T}{T_{m}} \cong 0.974$, theoretical expression of drying process can be shown as follows:

$$
\frac{M}{M_{0}}=\left\{1+\left[11.64 \cdot \frac{T}{T_{m}}\left(\frac{t}{t_{\infty}}\right)^{2}+120 \cdot\left(\frac{f}{f_{\infty}}\right)^{2}\left(\frac{t}{t_{\infty}}\right)\right] \alpha(t)\right\}^{-1}
$$

$\alpha(t)$ function is selected as follows in different frequency of EMW:

$$
\begin{aligned}
& \left.f=0 \mathrm{kHz} \Rightarrow\left(\frac{f}{f_{\infty}}\right)^{2}=0 \Rightarrow \alpha(t)=(0.4873151)\right) \times 1.84^{\left.-0.5+\left(\frac{t}{t_{\infty}}\right)^{2}\right]} . \\
& f=5 \mathrm{kHz} \Rightarrow\left(\frac{f}{f_{\infty}}\right)^{2}=0.025 \Rightarrow \alpha(t)=0.58752987 \times \mathrm{e}^{-\left(\frac{t}{t_{\infty}}\right)^{2}} \\
& f=10 \mathrm{kHz} \Rightarrow\left(\frac{f}{f_{\infty}}\right)^{2}=0.01 \Rightarrow \alpha(t)=0.2514707^{\left.-0.5+\left(\frac{t}{t_{\infty}}\right)^{2}\right]}
\end{aligned}
$$

$f=20 \mathrm{kHz}$ curve is falling on top of the curves of $f=0 \mathrm{kHz}$. In this case, EMW does not show the effects on drying process. Theoretical and experimental results of drying the banana in this condition have been presented in Figure 5.

3) The temperature of blown air $T_{m}=333^{\circ} \mathrm{K}\left(60^{\circ} \mathrm{C}\right)$

According the external environment temperature to be $T_{\infty}=27^{\circ} \mathrm{C}=300{ }^{\circ} \mathrm{K}$.

In case of $\frac{T}{T_{m}} \cong 0.974$, mass balanced equation of the drying process can be written as follows, empirical equation of $\alpha(t)$ function depending on the frequency of applied EMW is expressed as below:

$$
\begin{aligned}
& \frac{M}{M_{0}}=\left\{1+\left[11.64 \cdot \frac{T}{T_{m}}\left(\frac{t}{t_{\infty}}\right)^{2}+120 \cdot\left(\frac{f}{f_{\infty}}\right)^{2}\left(\frac{t}{t_{\infty}}\right)\right] \alpha(t)\right\}^{-1} \\
& f=0 \mathrm{kHz} \Rightarrow\left(\frac{t}{t_{\infty}}\right)^{2}=0 \Rightarrow \alpha(t)=(0.6869855) \times 1.83^{-\left[\frac{t}{t_{\infty}}+\left(\frac{t}{t_{\infty}}\right)^{2}\right]} \\
& f=5 \mathrm{kHz} \Rightarrow\left(\frac{t}{t_{\infty}}\right)^{2}=0.0025 \Rightarrow \alpha(t)=1.2543515 \times 10^{-\left(\frac{t}{t_{\infty}}\right)^{2}} \\
& f=10 \mathrm{kHz} \Rightarrow\left(\frac{t}{t_{\infty}}\right)^{2}=0.01 \Rightarrow \alpha(t)=0.12839 \times 0.007^{-\left[\frac{t}{t_{\infty}}-\left(\frac{t}{t_{\infty}}\right)^{2}\right]} \\
& f=20 \mathrm{kHz} \Rightarrow\left(\frac{t}{t_{\infty}}\right)^{2}=0.04 \Rightarrow \alpha(t)=0.15557422 \times 1.05^{-\left[0.5+\left(\frac{t}{t_{\infty}}\right)^{2}\right]}
\end{aligned}
$$

Experimental and theoretical results obtained from the drying of the banana in these conditions illustrated in Figure 6. In the all cases have been accepted as $t_{\infty}=20 \mathrm{~h}$ and $f_{\infty}=100 \mathrm{kHz}$.

\section{Conclusions}

One of the main problems for banana is transport problem. As is known, bananas are grown very quickly and start to rapidly deteriorate. One of the important methods that can prevent to this problem is drying of the banana. 


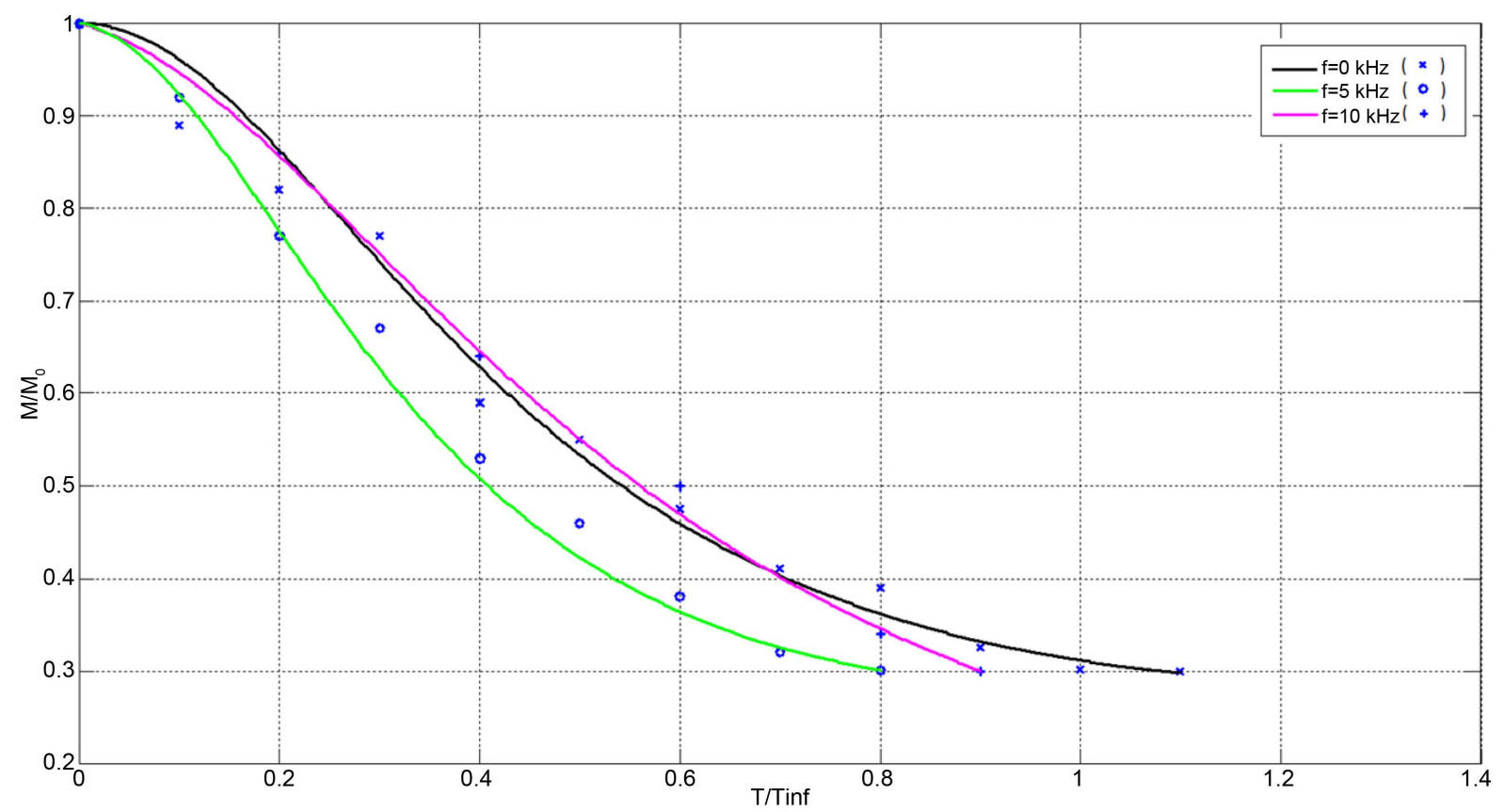

Figure 5. Experimental and theoretical curves of drying the banana under the influence of EMW for $T_{m}=323{ }^{\circ} \mathrm{K}$.

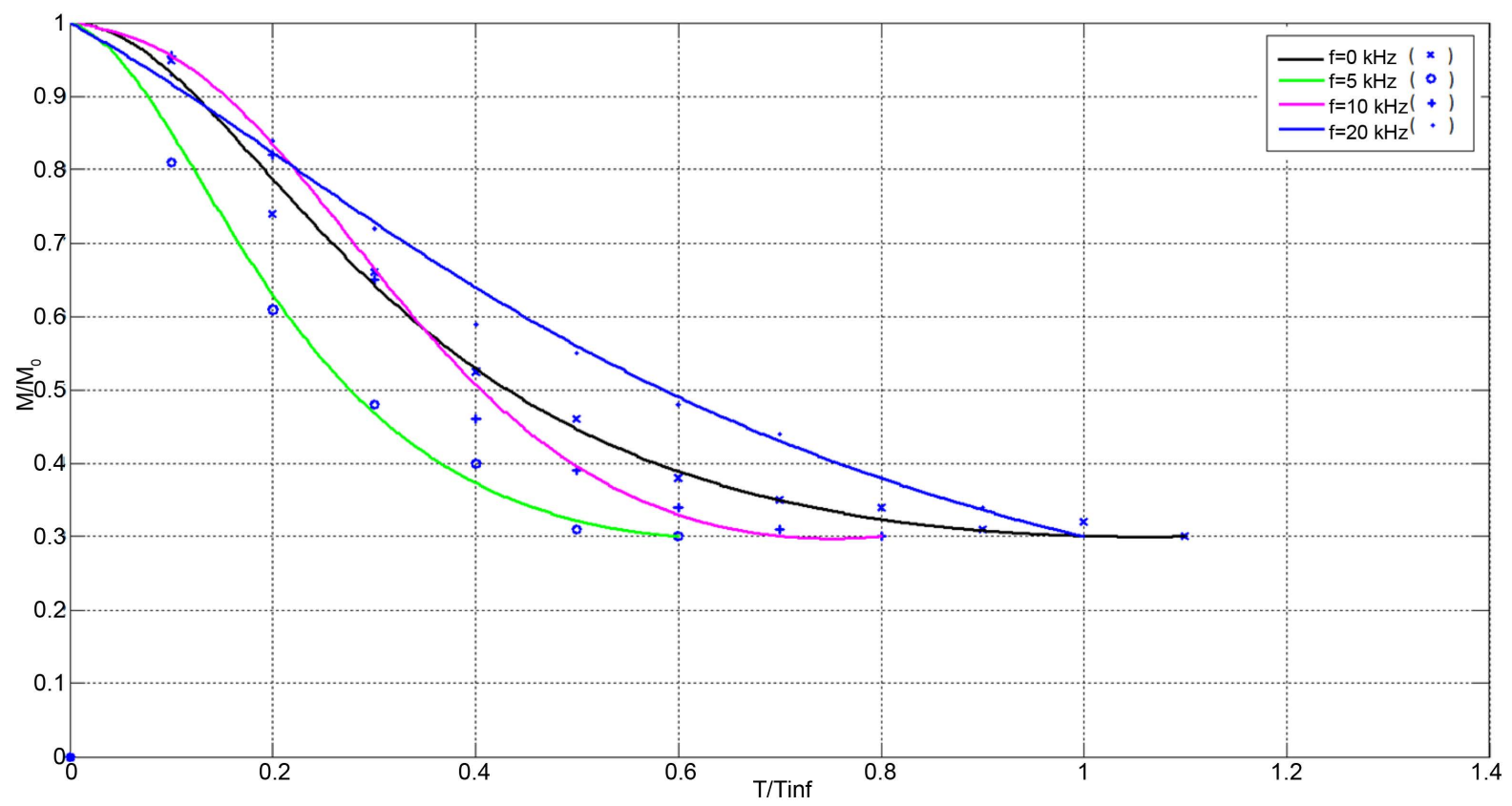

Figure 6. Experimental and theoretical curves of drying the banana under the influence of EMW for $T_{m}=333{ }^{\circ} \mathrm{K}$.

In this study, a method can reduce the drying time and can be stored while retaining the properties of banana has been investigated by experimental and theoretically and following results are obtained:

1) Blown air in convective drying with experimental way has been determined to be nearly $1.5 \mathrm{~m} / \mathrm{s}$.

2) Drying which is carried out at temperatures higher than $60^{\circ} \mathrm{C}$ leads to the change of color and tastes deterioration of banana.

3) Drying speed is possible to increase effectively with EMW effect. The drying speed has been determined to increase in frequencies which are lower than $15 \mathrm{kHz}$. The effect of EMW in $20 \mathrm{kHz}$ has a very low values and negligible. 
4) The mathematical model for a prediction for the drying speed, temperature and moisture distribution of the material also has been developed and new mathematical expressions have been obtained (Equation (7)).

5) At different temperatures convective $(f=0)$ and EMD's due ( $f=5 \mathrm{kHz}, 10 \mathrm{kHz})$ are obtained empirical expression of the diffusion coefficient nonlinear drying.

6) Experimental results are given in the table and make the banana curve of drying time. Herring to a humidity drying time can easily be determined from the table or graphics.

7) Obtained theoretical and experimental results have been observed to provide good blend well.

\section{References}

[1] Tayaraman, K. and Cupta, D.K. (2005) Drying of Fruits and Vegetables. In: Dekker, M., Ed., Handbook of Industrial Drying, New York, 643-690.

[2] Karim, M.A. and Hawlader. M.N. (2005) Drying Characteristics of Banana: Theoretical Modelling and Experimental Validation. Food Engineering, 70, 35-43. http://dx.doi.org/10.1016/j.jfoodeng.2004.09.010

[3] Maskam, M. (2001) Drying Shrinkage and Rehydration Characteristics of Kiwi Fruits during Not Microwave Drying. Journal of Food Engineering, 48, 177-186. http://dx.doi.org/10.1016/S0260-8774(00)00155-2

[4] Hayaloğlu, A.A., Karabulut, I. and Kelbaliyev, G.I. (2007) Matematical Modelling of Drying Characteristics of Strained Yoghurt in a Convective Type Tray-Dryer. Journal of Food Engineering, 78, 109-117. http://dx.doi.org/10.1016/j.jfoodeng.2005.09.006

[5] Likov, A.B. (1972) Isı sıcaklıktaransferi (Rusça), M. Energiya.

[6] Al-Muhteseb, A.H., McMinn, W.A. and Magee, T.R. (2004) Shrinkage, Density and Porosity Variations during Convective Drying of Patatostarchgel. Processing of the 14th Int. Drying Symposium, Sao Paulo.

[7] Hatamipoop, M.S. And Movla, D. (2003) Correlation for Shrinkage, Density and Diffisivity for Drying of Maize and Greenpeas in Afluidsed Bed with Energy Carried. Journal of Food Engineering, 59, 221-227. http://dx.doi.org/10.1016/S0260-8774(02)00461-2

[8] Aladjaniyan, A. and Ylieva, T. (2003) Influence of Stationary Magnetic Field on the Early of the Development of Tobacco Seeds. Journal of European Agriculture, 4, 131-137.

[9] Sadek, S.E., Fax, R.G. and Hurwitz, M. (1972) The Influence of Electrical Fields on Convective Heat and Vass Transfer from a Horizontal Surface under Forced Convection. Journal of Heat Transfer, 2, 144-148. http://dx.doi.org/10.1115/1.3449885

[10] Bird, R.R., Stewart, W.E. and Lightfood, E.H. (1960) Transport Phenomena. John Willey, London.

[11] Memmedov, A., Kelbaliyev, G. and Alisoy H. (2010) Solution of an Inverse Problem for Mass Tranfer in a Drying Process in Electro magnetic Field. Inverse Problems in Science and Engineering, 18, 723-736. http://dx.doi.org/10.1080/17415977.2010.492507

[12] Ratanadechoab, P., Aokip, K. and Akahorib, M.A. (2001) A Numerical and Experimental Study of Microwave Drying Using a Rectangular Wave Guide. Drying Technology, 19, 2209-223. http://dx.doi.org/10.1081/DRT-100107495

[13] Dincov, D.D., Parrott, K.A. and Percleous, K.A. (2004) A New Computational Approach to Microwave Heating of Two Phase Porous Materials. International Journal of Numerical Methods for Heat and Flow, 14. 783-802. http://dx.doi.org/10.1108/09615530410544319

[14] (1973) Elektromanyetik, Schaum’s on Tlins. Mc Graw Hill, Moscow.

[15] Griffiths, D.J. (1996) Elektromanyetik Teori. İstanbul.

[16] Bessonov, L.A. (1973) Elektrotekniğinteoriktemelleri. VesşayaŞkola, Moskova.

[17] Barrosa, M.Y. and Guine, R.P.F. (2012) Variation of Physical Properties of Banana along Drying Foreus. Musa Nana and Musa Cavendiskii, VII. Cocreso IBERICO DE AGROIN-Genierla 4CIENCIAS Hortikolas, 26-29 August 2012, Madrid.

[18] Bart-Plange, A., Ofori, H. and Asare, V. (2012) Thermal Properties of Cros Michel Banan Crow in Ghana, ARPH. Journal of Engineering and Applied Science, 7.

[19] Memmedov, A., Abbasov, T. and Şeker, M. (2014) Theoretical Modelling and Experimental Analysis of Drying Process in Electromagnetic Field. World Journal of Engineering and Technology, 2, 41-53. http://dx.doi.org/10.4236/wjet.2014.21005

[20] Boudriona, A. and Bonazzic, C. (2003) Changes in Aromatic Components of Banana Drying Ripening and Air-Drying. Lebens-Mittel-Wissenchaft Technology, 36, 633.

[21] Maskon, M. (2000) Microwave and Microwave Finish Drying of Banana. Journal of Food Engineering, 44, 71-78. 
http://dx.doi.org/10.1016/S0260-8774(99)00167-3

[22] Phoungshandang, S. and Woods, J. (2000) Mousture Diffusion and Desorpsionisotherus of Banana. Journal of Food Science, 65, 652.

[23] Unal Ümit, M. (2005) Properties of Polyphenol Oxidase from Anamur Banana. Food Chemistry, Musa Covendishii.

[24] Wikipedia, the Free Encyclopedia.

[25] Frolov, V.F. (1987) Modelling of the Drying Processes of the Dispertions Materials. Chemical ed. Leningigrad. (In Russian) 